\title{
HREM AT ORTHOGONAL PROJECTIONS OF GaAs ISLANDS ON SILICON
}

\author{
F. A. Ponce ${ }^{\circ}$ and C. J. D. Hetherington* \\ - Xerox Palo Alto Research Center, Palo Alto, CA 94304 \\ * NCEM, Lawrence Berkeley Laboratory, 1 Cyclotron Road, Berkeley, CA 94720.
}

HREM studies typically examine only one projection of a structure and information in the electron beam direction is lost. In most cases, the structe 'e in this direction is uniform and already known, but in others a second projection needs $t$ he ohserved. This could involve preparing a second specimen sectioned at right angles 1 the first, or as deseribed here, tilting $a$ specimen through $\pm 45^{\circ} 1$ and observing the same volume in orthogonal projections. The specimen used here was of GaAs islands on $<001>$ silicon, examined in the Atomic Resolution Microscope at LBL.

In the effort to grow defect-free GaAs films on silicon substrates, understanding of the early stages of growth is required 2,3. Fur this experiment we chose a specimen of ultra-thin GaAs grown on silicon substrate by metal-organic chemical vapor deposition (MOCVD). The GaAs was grown at $550^{\circ} \mathrm{C}$ for a nominal thickness of $20 \mathrm{~nm}$ from trimethyl gallium and arsine sources. The growth conditions lead to three-dimensio :al growth of islands bound by $\{111\}$ A planes, terminated on Ga layers 4 . The $\langle 100\rangle$ direstion of the silicon structure has a four-fold symmetry. The sphalerite structure of GaAs he only a two-fold symmetry in the $\langle 100\rangle$ orientation. Because of this difference a symmetry, two basic configurations of GaAs islands exist on $<001>$ silicon having lo.ay axes parallel to [110] or [1-10] directions. This has been observed in planar views, and individual $\{110\}$ cross sections have revealed the two possible projections of the islands 4 . However, no single island has been examined in detail under orthogonal projections.

For this study, a sample with appropriately spaced islands was chosen so that their images would not overlap in thin sections. An amorphous silicon layer was deposited to protect the islands during ion milling, and a [100] cross section was prepared. The specimen was aligned in the holder so that the interface lay midway between the $\pm 40^{\circ}$ tilt axes where the net tilt approaches $\pm 55^{\circ}$. The ARM was operated at $800 \mathrm{kV}$ and images taken at the [110], $[100]$ and $[1-10]$ zone axes as shown in figure 1 and explained schematically in figure 2 . The mechanical stability of the holder at $45^{\circ}$ tilt allowed $0.17 \mathrm{~nm}$ spaced $\{113\}$ fringes to be observed in an adjacent island. Beam alignment was preserved between tilts by focussing with the specimen height control.

From the images presented here, the anisotropy between the $[110]$ and $11-10]$ projections of the $\mathrm{GaAs}$ islands is evident. In addition to the difference in shape, the defect structure is strikingly different: stacking faults are quite common in the [1-10] but virtually absent in the [110]. This is expected to be due to the anisotropic [100] growth process of GaAs. This work demonstrates the feasibility of obtaining orthogonally projected HRTEM views of the same objects in order to provide detailed information of the 3-D atomic structure.

\section{References}

1. R. Hull, S. J. Rosner, S. M. Koch and J. S. Harris, Jr., Appl. Phys. Lett. 49 (1986) 1714.

2. F. A. Ponce et al. Materials Science Forum 10 (1986) 205.

3. D. K. Biegelsen et al. Appl. Phys. Lett. 52 (1988) 1779.

4. F. A. Ponce, G. B. Anderson, H. Chung, to be published.

5. The authors thank G. B. Anderson for assistance in sample preparation. This work was partially supported by the Director, Office of Energy Research, Office of Basic Energy Sciences, Materials Science Division of the U. S. Department of Energy under contract ¿). DE-ACO3-76SF00098. 


\title{
Figure Captions
}

Figure 1: HRTEM micrographs of single GaAs island shown in (a) [100], (b) [110], and (c) [1-10] projections. From image in (c) the TEM specimen thickness is measured to be $22 \mathrm{~nm}$. Island height is $29 \mathrm{~nm}$.

Figure 2: Schematic diagram of GaAs island morphology (a) TEM section of island bound by $\{111\} A$ (original surfaces, shaded) and $\{100\}$ (TEM specimen surfaces) planes, (b) TEM section of island (shaded) with projected axes indicated, (c) projections shewn in

Figure 1.

\section{DISCLAIMER}

\begin{abstract}
This report was prepared as an account of work sponsored by an agency of the United States Government. Neither the United States Government nor any agency thereof, nor any of their employees, makes any warranty, express or implied, or assumes any legal liability or responsibility for the accuracy, completeness, or usefulness of any information, apparatus, product, or process disclosed, or represents that its use would not infringe privately owned rights. Reference herein to any specific commercial product, process, or service by trade name, trademark, manufacturer, or otherwise does not necessarily constitute or imply its endorsement, recommendation, or favoring by the United States Government or any agency thereof. The viaws and opinions of authors expressed herein do not necessarily state or reflect those of the United Stales Government or any agency thereof.
\end{abstract}




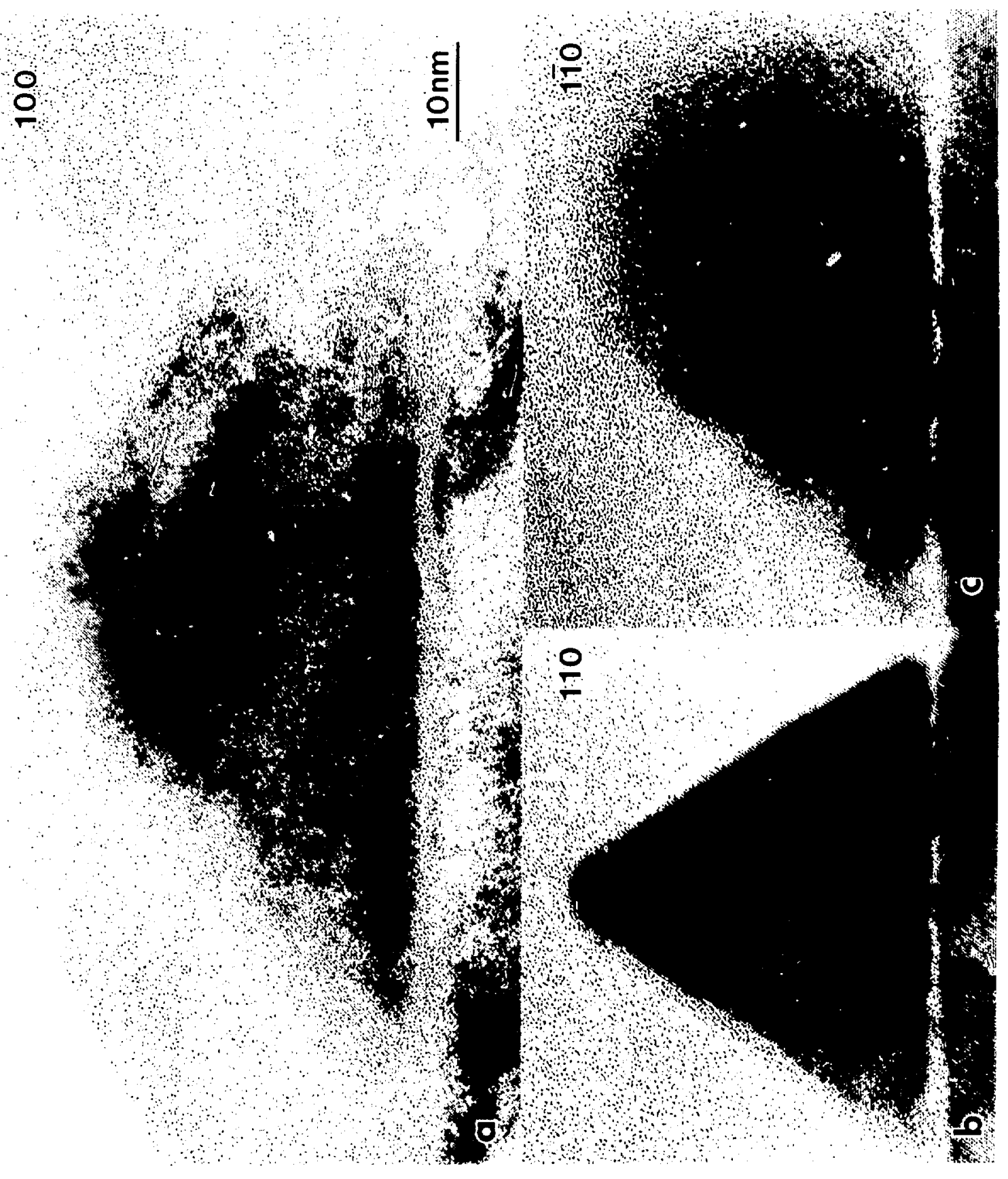




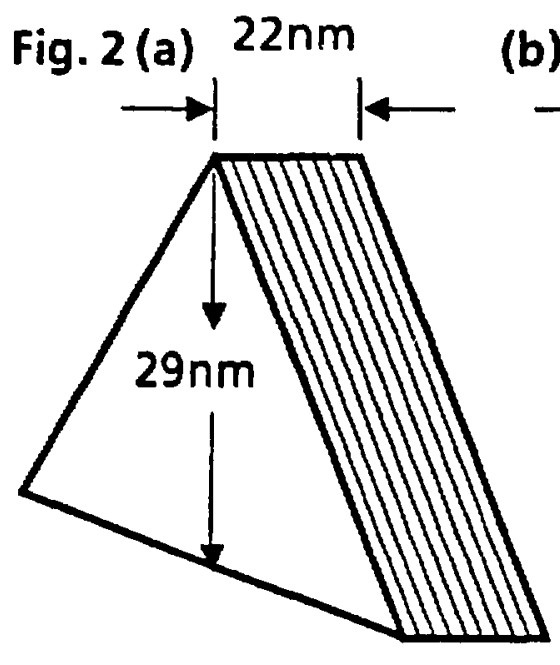

(c) (b) $22 \mathrm{~nm}$

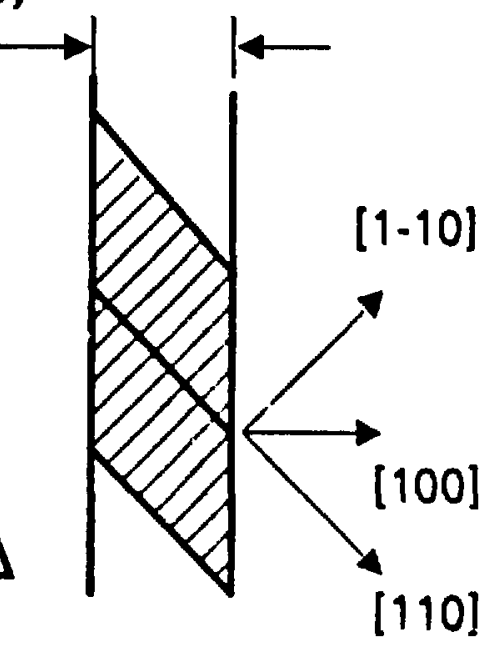

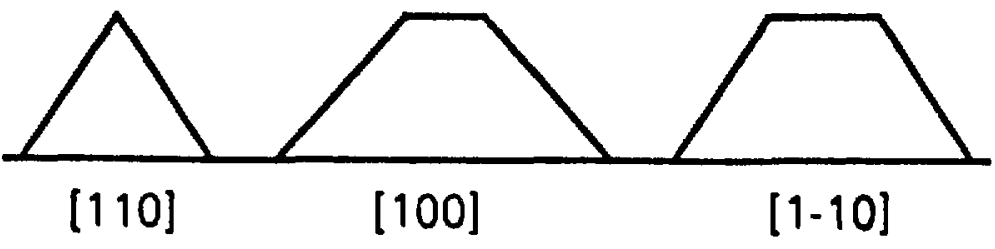

XBL 895-1815

FIGURE 2 